\title{
The Natural Cycle: WHY Economic Fluctuations are Inevitable. A Schumpeterian Extension of the Austrian Business Cycle Theory
}

\author{
Carmelo Ferlito*
}

\author{
INTI International College Subang, Subang Jaya, and Institute for Democracy and Economic Affairs, Kuala \\ Lumpur, Malaysia
}

\begin{abstract}
The conventional version of Austrian business cycle theory focuses on a temporary imbalance between natural and monetary rates of interest. When, because of the role of monetary authorities in defining the monetary rate, the two values are in a situation of imbalance, the resulting expansion stage is followed by a recession. On the other hand, if instead the expansive phase arises without any interference by monetary authorities but through re-adaptation of the productive structure to a modified structure of temporal preferences, a period of sustainable growth begins that will not be followed by a crisis. The purpose of this essay is to demonstrate, on the other hand, that because of profitexpectations and the combined action of Schumpeterian elements (imitations-speculations and the 'creation of money' by banks), even a so-called 'sustainable' boom will be affected by a liquidation and settling crisis. What distinguishes the latter situation from the conventional case of imbalance between monetary and natural rates is not the onset or otherwise of a crisis but, rather, its intensity and duration. We will define as natural an economic cycle characterised by a stage of expansion considered to be 'sustainable' in the Austrian theory but followed by an inevitable readjustment crisis.
\end{abstract}

Keywords: Austrian Economics, Hayek, Schumpeter, Business Cycles, Expectations, Innovation.

\section{INTRODUCTION. ON THE INEVITABILITY OF THE BUSINESS CYCLE}

Ferlito $(2013)^{1}$ attempted to outline an integrated theory of the business cycle that, making the most of the long-standing Austrian tradition, would be capable of enhancing it with some external contributions, in particular those of Arthur Spiethoff and Mikhail TuganBaranovskij.

Starting from this analysis, here we will attempt to clarify a point that perhaps remained rather vaguely outlined and only in the background in the book. In our opinion, cyclical fluctuations are to some extent inevitable, even where development is generated in a manner that Austrian economic analysis defines as 'sustainable'. While agreeing with all the basic precepts of the Misesian tradition, we nevertheless believe that the more complex Hayekian vision, supported by a number of Schumpeterian elements, can demonstrate how every boom, however sustainable, is always followed by a depression. What distinguishes sustainable and unsustainable development, therefore, is not the onset of crisis but its intensity and the unfolding of prolonged depression. We could define as natural an economic cycle characterised by a stage of

*Address correspondence to this author at the BT-11-8 Saujana Residency, SS16/1, 47500 Subang Jaya, Malaysia; Tel: +60-19-2394148;

E-mail: carmelo.ferlito@gmail.com

JEL Classification: B13, B25, B53, D84, E32, E52, E58, O33.

\footnotetext{
${ }^{1}$ Deepening what already started with Ferlito (2010).
}

expansion considered to be 'sustainable' in the Austrian theory but followed by an inevitable readjustment crisis.

As we clarified in Ferlito (2013:30), capitalism without fluctuations does not exist ${ }^{2}$. Marx was the first to realise this ${ }^{3}$; Marx was

clearly aware of the existence of the business cycle. He was perhaps the first economist who developed a crisis theory. Not only; but he was evidently aware of the uniqueness of the cycle problem and the development problem: the cycle, for Marx, is the form that accumulation development - effectively takes in capitalist society. (Sylos Labini [1954] 1977:31).

The same awareness is to be seen in Schumpeter and Spiethoff.

Inasmuch, cycle and development phenomena are closely connected, in Schumpeter's concept. As for Marx, cyclic fluctuations are not seen as fluctuations around a hypothetical line of equilibrium. The cycle, inasmuch, is the form that the development process takes on; the one

${ }^{2}$ Huerta de Soto (1998:468) points out that «[o]ne of the more curious points on which a certain agreement exists [between Marxian and Austrian analysis] relates precisely to the theory of the crises and recessions which systematically ravage the capitalist system».

${ }^{3}$ Rothbard ([1969] 2009:13). 
and the other are two aspects of the same reality. (Vitello 1965: 46).

And Spiethoff ([1925] 2002:112), concludes that «the cyclical upswings and downswings are the evolutionary forms of the highly developed capitalist economy and their antithetic stimuli condition its progress». Realising that the cyclic form is typical of capitalist development is also echoed in the words of Italian Marco Fanno, who in 1931 wrote:

$[W]$ e need now to ask whether these disturbances and the long-duration production cycles are not, by chance, the factors determining business cycles; that is, whether the long duration of production cycles may not represent a condition sufficient to make the wave-like economic pattern of modern economies inevitable and provide an explanation for it. Valid arguments would appear to back up the affirmative theory. (Fanno [1931] 2002:248-249).

Supported by the testimony of such economists, we shall seek to demonstrate how, even using the Austrian approach, one may reach the conclusion that cyclic fluctuations are inevitable. To this end, the Misesian approach, that identifies manipulation of the interest rate and inflationary policies as the main cause of crises, may only be useful in part for our analysis. The Mises-Rothbard direction, in fact, seems to us to be too dogmatic and unable to grasp fully the phenomenology of capitalistic development. On the contrary, Hayek's approach, which at times seems to be contradictory, is better suited to being impregnated with different contributions, in order better to outline the fundamental aspects of growth dynamics in capitalist economies.

\section{PREFERENCES AND THE RATE OF INTEREST. THE FRAMEWORK OF THE ABCT}

The role of expectations is crucial for our analysis. Yet we must arrive there gradually, starting off from certain conventional elements in the Austrian business cycle theory. They are time preferences and the intertemporal structure of production.

According to the law of time preference, «other things being equal, humans always place present goods higher than future goods on their scales of value» (Huerta de Soto [2000] 2010:50); starting from this assumption, the Austrian School comes to a definition of interest rate radically opposed to that of the dominant theory ('cost of money'). We may define «the interest rate [as] the market price of present goods in terms of future goods» (Huerta de Soto [2000] 2010:51). It is therefore limiting and profoundly wrong to define the interest rate as the cost of money. Moving closer to a more medieval concept, we can see how what is normally called $i$ is more related to the concept of time than to the concept of money. The capital market is only a particular market for goods, where the action of the interest rate is the most evident but not the only one. In this particular market, supply - sellers - is represented by consumers, those who have present goods and are willing to forego them to some extent, defined precisely by the interest rate ${ }^{4}$. One of the forms in which such foregoing takes place is savings; consumers forego present money as a function of future money; they therefore offer money to the market. Who represents demand? Entrepreneurs who need money today in order to implement their industrial projects. Therefore, for the capital market, the natural interest rate is that particular rate which allows supply (consumer savings) to meet demand (entrepreneur investments).

Yet the law of time preference does not apply only to the capital market. It should be extended to the entire economic system, where the natural rate is consequently that rate of equilibrium which reflects the temporal preferences of economic agents. Obviously, this is a theoretical level but one to strive for. The monetary rate, on the other hand, in contemporary economic systems is set imperiously by monetary authorities.

Hayek ([1933] 1975:145) says that

an equilibrium rate of interest would then be one which assured correspondence between the intentions of the consumers and the intentions of the entrepreneurs. And with a constant rate of saving this would be the rate of interest arrived at on a market where the supply of money, capital was of exactly the same amount as current savings.

The capital market, so highly emphasised by the dominant theory when discussing interest rates, is therefore only one among many markets. On the other hand, it is possible to define an interest rate for the

${ }^{4}$ Huerta de Soto ([2000] 2010:51-52) 
economic system, which measures the more general structure of time preferences. As regards consumers, it defines the relationship between consumption and saving. In the case of entrepreneurs linked to investments, it measures the propensity towards the future, that desire to undertake long-term projects in the investment goods sector that makes the production structure more circular and the production period longer, compared to investments in consumer goods and investments having a faster realisation cycle.

In a future-oriented system, consumers are more savings-oriented, thereby encouraging the accumulation of loanable funds that can be used by entrepreneurs in long-term projects. A present-oriented society, in contrast, has a greater propensity towards consumption on the consumer side, while investors do not lengthen the production process. Situations of equilibrium may exist in a system with a high time preference as on the contrary. It is not the sum of one of the aggregates that defines this equilibrium but the possibility for time preferences to come together through the free exercise of the entrepreneurial function that each person enacts in relationships with other people in the process of satisfying needs of various kinds.

The level of equilibrium for a combination of time preferences is measured by the natural interest rate, which in turn corresponds to a well-defined structure of the production process. The key element that, by fuelling a modification of the inter-temporal structure of production, generates a cycle of expansion and crisis is given by a change in level of the natural rate. According to the traditional Austrian perspective, if the mutation of the natural interest rate reflects a change in time preferences, this generates a positive expansive cycle, which will not be followed by a painful crisis (and we will seek to demonstrate, on the other hand, that a readjustment crisis is inevitable). Conversely, if the rate - rather than settling in response to interaction on the free market of entrepreneurial action of different individuals - is set by central planning authorities which follow precepts of monetary policy or political motivations, the expansive cycle that will be followed by monetary expansion will generate a crisis. In fact, there will have been no change in the natural rate and no change in time preferences; the change generated in the structure of production will be the outcome of a false signal, the manipulation generated by monetary authorities.

It is therefore crucial to study whether and how the banking system and central banks affect the monetary rate, which plays a guiding or 'signal' role, in defining the time preferences of individuals: spending vs. savings for savers and consumer goods vs. capital goods for entrepreneurs. In a certain sense, we could say that action by monetary authorities means that players are not free to explore what the natural rate would be, because they are oriented to observe what is defined by the central banks.

Monetary policy is neutral if «it does no more than intermediate between savers and investors. If policy is neutral, changes in the supply of credit are governed by changes in the supply of planned saving" (O'Driscoll and Rizzo [1985] 2002:230). Which is to say that growth in loans for investments may generate a sustainable boom, which will not be followed by an economic crisis, only if it is based on increased savings, i.e. on an increase in resources actually available to investors, real rather than virtual capital. In fact, a situation of this kind would correspond to a change in the structure of time preferences.

The direct effect of a fall in time preferences is a fall in the loan rate of interest and an increase in the quantity of loanable funds supplied and demanded. This result requires only that marketclearing forces prevail in the market for loanable funds. [...] The change in time preferences simply means that the entrepreneur is performing his task under the conditions of a lower rate of interest and a greater availability of credit. All that needs to be said here about the ability of entrepreneurs to adapt successfully to these changed credit conditions is that self-correcting forces are at work: those entrepreneurs who do successfully adapt will tend to make profits and hence will gain command over greater quantities of resources, while those who do not will tend to make losses and hence will lose command over resources. (O'Driscoll and Rizzo [1985] 2002:205).

Conversely, if credit is artificially increased, this creates the premises for unhealthy expansion based on erroneous investments by entrepreneurs, who implement bad investments (malinvestments) because they are driven by a price or a rate that do not reflect the structure of time preferences. The unhealthy boom will necessarily be followed by a recession. And, precisely as is happening today, «investment cycles 
generally finish in a credit crisis with a simultaneous and sudden financial "crisis" for many businesses" (O’Driscoll and Rizzo [1985] 2002:237).

How can such a disproportion between the natural rate and the monetary rate be generated? This situation may arise in two ways. Either the monetary rate is driven by someone below the natural rate or the latter rises above the first. The first situation is perhaps the easiest to imagine and the one normally taken into consideration by Mises; the Central Bank plays with the interest rate, believing in the automatism whereby a low rate, stimulating investments, can stimulate a stagnant economy; the monetary authority is usually supported in this by a carefree credit policy on the part of banks, which hit the accelerator to create enormous packs of junk loans which they then put on the market and securitize, with the intention of reaping massive profits and then leaving the game board while the going is still good. It is true that such combined action may create economic growth, but it is virtual and in any case followed by a recession, precisely as is happening today. This is the typical error evident in monetarist economic theory.

Yet there is also a second possibility, which may arise separately or in combination with the foregoing. The natural rate rises above the monetary rate; this is the theoretical novelty introduced by $\mathrm{Hayek}^{5}$. The situation occurs through positive profit expectations. If entrepreneurs, whose psychological dynamics are fundamental in any economic process, are pervaded by a positive sentiment, i.e. if they are convinced they can start profitable industrial projects and have excellent profit expectations, they will be encouraged to request more credit in order to begin longer production processes. This means they have changed their time preferences in becoming more future-oriented. The natural rate rises, as the market process attempts to attract new savings to re-balance the change in time preferences, for the moment only on the part of entrepreneurs, while the supply of savings has not changed. In this case, central banks should immediately raise official rate to align it with the unilateral change in time preference (only entrepreneurs are asking for more credit, while the offer - i.e. savings - has not grown). In doing so, the other part of the market - consumers - will be encouraged to save more, thereby providing the market with additional monetary resources capable of meeting

\footnotetext{
${ }^{5}$ Hayek ([1929] 1966:147)
}

increased demand by entrepreneurs and consequently allowing a soundly based investment cycle to begin. This shows how an expansive cycle may be set in motion even by higher rates and not only in the presence of a low rate of interest. If realignment between the monetary rate and the natural rate does not take place, i.e. the monetary rate is still held artificially low, again in this case there will be an expansive cycle followed by a depression.

\section{UNCERTAINTY AND EXPECTATIONS}

Uncertainty is one of the key elements in the economic process. On a closer look, we cannot even imagine that opportunities for profit will arise outside a context of uncertainty and disequilibrium ${ }^{6}$. In fact, without uncertainty, all occasions for profit would have already been exhausted; in an uncertain context, on the other hand, entrepreneurs who make the best forecasts or people who, for various reasons, best fulfil their expectations and plans, enjoy an advantage created precisely by the fact of knowing better how to move in such a context, how to imagine the future better'?

The main features of true uncertainty «are the inherent unlistability of all possible outcomes resulting from a course of action, and the complete endogeneity of the uncertainty» (O'Driscoll and Rizzo [1985] 2002:100). Inasmuch, if uncertainty is endogenous to the system, an intrinsic feature, it cannot but originate a constantly changing system, in which human action is essentially guided by expectations: expectations determined by preferences, that in turn generate any kind of action. Such action is intrinsically uncertain, in that nothing, a priori, ensures that such expectations will be realized.

In such a system, it is evident that even the acquisition of new information cannot eliminate uncertainty. The accumulation of knowledge merely changes the uncertainty ${ }^{8}$. The information content is not complete, only larger. Aspects affecting the pursuit of action have changed but are not complete. The outlines on the horizon, and consequently the uncertainty in relation to the complete form, are different. It is therefore clear that the theoretical bridge between preferences and action is made of expectations: desires as regards the future and the

\footnotetext{
${ }^{6} \operatorname{Rizzo}(1979: 10)$.

${ }^{7}$ On the role of entrepreneurs in a dynamic market process, marked with uncertainty, see in particular Kirzner (1973:30-87).

${ }^{8}$ O'Driscoll and Rizzo ([1985] 2002:102-103).
} 
scenarios awaiting us take place, determining our possibility for action. As pointed out by Lachmann (1979:65), the evolution of the concept of preferences towards the concept of expectations can be considered as one of the major innovations produced by methodological subjectivism in the last century.

It is evident that expectations cannot be considered, as in neoclassical theory, as a static element fixed at the beginning of the match and then unchangeable until the final result is achieved. On the contrary, since human action is a dynamic process that unfolds over time, the set of information available to players constantly changes, bringing about a continual modification of expectations, objectives and plans.

The economist who most deeply analysed the concept of expectations, re-interpreting them dynamically and inserting them in the Austrian theoretical paradigm, was Ludwig M. Lachmann. Acknowledging Keynes's important function in having introduced the concept of expectations in an organic way with $A$ Treatise on Money (1930), and referring Shackle's contribution, Lachmann sought to engage his own contribution completely within the Austrian tradition, albeit with the necessary distinctions. In particular, he felt that the Austrians missed the opportunity to insert expectations within their own thinking in an organic way.

It is a curious fact that, when around 1930 (in Keynes's Treatise on Money) expectations made their appearance in the economic thought of the Anglo-Saxon world, the Austrians failed to grasp with both hands this golden opportunity to enlarge the basis of their approach and, by and large, treated the subject rather gingerly. (Lachmann 1976:58).

In truth, Lachmann's criticism may even seem to be too severe. Hayek ([1929] 1966:147) had already recognised the central role of expectations, when he claimed that positive expectations of profit can guide entrepreneurs to change their preferences, becoming more future-oriented, thereby leading to a rise in the equilibrium interest rate. This step was also central to Hayek's fundamental work (1933); furthermore, Hayek in 1937 discussed in details the problem of knowledge ${ }^{9}$.

\footnotetext{
${ }^{9}$ Hayek ([1937] 1958)
}

However, Lachmann sought to be more radical: he acknowledged that Hayek had discussed the question of expectations precisely where we also found it; yet, he 'accused' him of not having worked enough on the causes and consequences that a divergence in expectations can generate ${ }^{10}$. The German economist therefore embraces Shackle's concept of the kaleidic society, «a society in which sooner or later unexpected change is bound to upset existing patterns, a society "interspersing its moments or intervals of order, assurance and beauty with sudden disintegration and a cascade into a new pattern"» (Lachmann 1976:54).

Expectations are consequently the hallmark of a society made of real players which, starting precisely from them, form their own plans for the future, meeting and modifying knowledge and the plans themselves. This generates the kaleidoscopic world, a world where change is constant.

In a kaleidoscopic society, moreover,

the equilibrating forces, operating slowly, especially where much of the capital equipment is durable and specific, are always overtaken by unexpected change before they have done their work, and the results of their operation disrupted before they can bear fruit. [...] Equilibrium of the economic system as a whole will thus never be reached. (Lachmann 1976:6061).

Expectations, by generating plans, generate economic processes ${ }^{11}$. They then change during the process. With the accumulation of knowledge, the scenario constantly changes. Yet, bear in mind, expectations are not something 'up in the clouds'; without them, there is no economic activity as such; it is starting from expectations that every decision is taken with the intention of making a profit or achieving personal satisfaction. However, these attempts emerge in a context of imperfect knowledge and an unexpected and unpredictable future ${ }^{12}$.

\section{EXPECTATIONS AS 'AUSTRIAN' BRIDGE: ENTREPRENEURSHIP AND IMITATION IN SCHUMPETER}

The intellectual and human career of Joseph A. Schumpeter is undoubtedly among the most interesting

\footnotetext{
${ }^{10}$ Lachmann (1976:58).

${ }^{11}$ As Hicks ([1979] 2002:284) said, «production will not be undertaken unless expectations are formed $"$.

${ }^{12}$ Lachmann ([1982] 2002)
} 
in the sphere of the history of economic thought. Scholars have focused, by no means wrongly, especially on the aspects of discontinuity between his thinking and the Austrian tradition ${ }^{13}$, emphasising on the other hand his affinities with the German economic thinking. We, on the contrary, will attempt to bring out certain elements in Schumpeterian analysis capable of completing, rather than contradicting, the Austrian business cycle theory. To do this, we must not take into account merely the cyclic analysis developed in Schumpeter's work $(1939,1964)$; we must, rather, backtrack to a number of key points highlighted by Schumpeter in his Theorie (1911).

The development of an accomplished analysis of the business cycle is a process that Schumpeter carried out in the course of thirty years of theoretical reflection. Even as a young man, he cared deeply about developing a theory capable of interpreting the actual economic processes typical of capitalist dynamics. Yet his central early work, Theorie (1911), did not emphasise cyclical dynamics. He focused on the elements that can generate development ${ }^{14}$, or the "spontaneous and discontinuous changes in the channel of the circular flow and [the] disturbances of the centre of equilibrium» (Schumpeter [1911] 1983:65). And he identifies the entrepreneurial function generating innovation as the key element for development. The development generated by innovations was later the fulcrum of his cyclical analysis (1939) ${ }^{15}$.

Development is the essential fact of capitalist reality; but what sets it in motion? An innovation, understood in a broader sense than the one we generally attribute to this term; innovation is the discontinuous introduction of 'new combinations' ${ }^{16}$.

Innovation does not strictly imply a technological change, nor does it necessarily imply the exploitation of unused resources. Yet, if innovation is the factor that sparks off development, two fundamental subjects allow innovation itself to come about; the entrepreneur and the banker. In particular, the entrepreneur is not

\footnotetext{
${ }^{13}$ It may simply be mentioned that Schumpeter, in 1925 , was given a Professorship at the University of Bonn at the expense of Mises and thanks to friendship with Spiethoff. "Bonn conquered!" was the jubilant comment Schumpeter sent in a telegram to his fiancé. See Nasar (2011:271).

${ }^{14}$ Development in Schumpeter's point of view must be absolutely distinguished from growth, which can also occur even a stationary condition, in being distinguished by the absence of structural changes. In this regard, see also Lachmann ([1940] 1977:271).

${ }^{15}$ Schumpeter ([1939] 2005; [1964] 2008)

${ }^{16}$ For a complete list of the innovations contemplated by the Austrian economist, see Schumpeter ([1911] 1983:66).
}

the inventor and is not necessarily a scientist, but the person who identifies the possibility of applying the invention to the production process, thereby allowing the invention to become innovation (the invention, in itself, might be absolutely irrelevant for the purposes of economic exploitation). The banker, however, is the subject who enables the entrepreneur to obtain the means to realise the innovation, in having the fundamental function of creating purchasing power.

Between Theorie and Business Cycles, Schumpeter took a profound theoretical and methodological path. While holding firm to certain points in his previous theoretical analysis, he matured a more complex vision in which the role of innovation is released from entrepreneurial action, given the oligopolistic development of the capitalist system, and becomes the central element of cyclical dynamics.

For Schumpeter, the wave pattern (cycle) is the form assumed by economic development in the capitalist era. Yet, assuming that it all starts from any point of static balance, what sets the cyclical trend in motion? Schumpeter identifies external causes and internal causes within the economic system; as regards the former (wars, earthquakes, etc.) the economist had nothing to say, while the latter are precisely innovations, which, in being a typical economic topic, certainly be analysed by the scientist ${ }^{17}$. Schumpeter outlines his theory of the business cycle through three approximations.

As regards the first, let's assume that we set off from a situation of perfect static equilibrium in which assumptions of perfect competition, constant population, lack of savings and everything needed to meet the requirements of the circular flow ${ }^{18}$ (Schumpeter calls such a situation of equilibrium the 'theoretical standard' ${ }^{19}$ ) hold true. It is also assumed that, in the capitalist society model, there will always be the possibility of new combinations and people capable and willing to implement them (their motivation is the prospect of profit).

Some people, then, conceive and work out with varying promptness plans for innovations associated with varying anticipations of profits, and set about struggling with the obstacles incident to

\footnotetext{
${ }^{17}$ Schumpeter ([1964] 2008:65-66).

${ }^{18}$ Schumpeter ([1964] 2008:132-133).

${ }^{19}$ Schumpeter ([1964] 2008:29-38).
} 
doing a new and unfamiliar thing [...] we suppose that he founds a new firm, constructs a new plant, and orders new equipment from existing firms. The requisite funds he borrows from a bank. On the balance acquired by so doing he draws, either in order to hand the checks to other people who furnish him with goods and services, or in order to get currency with which to pay for these supplies. [...] he withdraws, by his bids for producers' goods, the quantities of them he needs from the uses which they served before.

Then other entrepreneurs follow, after them still others in increasing number, in the path of innovation, which becomes progressively smoothed for successors by accumulating experience and vanishing obstacles. (Schumpeter [1964] 2008:133134).

What we note from the foregoing excerpt? Firstly, Schumpeter assumes that entrepreneurs immediately spend their deposits, except for a minimum reserve. Secondly, since there are no unused resources at the outset (given the circular flow hypothesis), the prices of production factors will increase, as well as monetary incomes and the interest rate. Thirdly, revenue will also increase, in line with the expenditure by entrepreneurs in investment goods, alongside those of workers, momentarily employed with higher wages, and those of everyone receiving all those higher payments ${ }^{20}$. However, up to this point, it is legitimate to assume that there has not yet been an increase in production ${ }^{21}$. This is what happens until the plant of the first entrepreneur begins to run ${ }^{22}$.

Then the scene begins to change. The new commodities-let us say, new consumers' goods-flow into the market. They are, since everything turns out according to expectation, readily taken up at exactly those prices at which the entrepreneur expected to sell them. [...] A stream of receipts will hence flow into the entrepreneur's account, at a rate sufficient to repay, during the lifetime of the plant and equipment originally acquired, the total debt incurred plus interest, and to leave a profit for the entrepreneur. [...] the new firms, getting successively into working order and throwing their products into the market of consumers' goods, increase the total output of consumers' goods [...]. (Schumpeter [1964] 2008:136).

Such new goods, according to Schumpeter, enter the market too quickly to be absorbed smoothly. In particular, the old enterprises and the pursuers have several possible scenarios before them, but there is no fixed rule: some become part of the new scenarios, others close because they are unable to adapt, others still seek rationalization ${ }^{23}$. However, the competitive advantage of the driving company tends to fade, since, as the products progressively come on to the market and the debt repayments quantitatively increase in importance, entrepreneurial activity tends to diminish to the point of disappearing altogether ${ }^{24}$. As soon as entrepreneurial impetus loses steam, pulling the system away from its previous area of equilibrium, the system embarks on a struggle towards a new equilibrium. The initial outline of a cyclic pattern can be seen $^{25}$.

When we look at the skeleton, we behold the picture of a distinct process in time which displays functional relations between its constituent parts and is logically self-contained. This process of economic change or evolution, moreover, goes on in units separated from each other by neighbourhoods of equilibrium. Each of those units, in turn, consists of two distinct phases, during the first of which the system, under the impulse of entrepreneurial activity, draws away from an equilibrium position, and during the second of which it draws toward another equilibrium position.

Each of those two phases is characterized by a definite succession of phenomena. The reader need only recall what they are in order to make the discovery that they are precisely the phenomenon which he

\footnotetext{
${ }^{20}$ Schumpeter ([1964] 2008:134).

${ }^{21}$ Schumpeter ([1964] 2008:135).

${ }^{22}$ Schumpeter ([1964] 2008:136).
}

${ }^{23}$ Schumpeter ([1964] 2008:137-138).
${ }^{24}$ Schumpeter ([1964] 2008:138).
${ }^{25}$ Schumpeter ([1964] 2008:142). 
associates with "prosperity" and "recession": our model reproduces, by its mere working, that very sequence of events which we observe in the course of those fluctuations in economic life which have come to be called business cycles and which, translated into the language of diagrams, present the picture of an undulating or wavelike movement in absolute figures or rates of change. (Schumpeter [1964] 2008:142).

A number of important observations derive from this initial draft:

- progress makes the economic mechanism unstable and makes it move in accordance with a cyclical trend ${ }^{26}$;

- $\quad$ prosperity and recession do not coincide with the concepts of wealth and misery normally attributed to them; prosperity, moreover, is a move away from a situation of balance, while recession is a return towards it; this is quite unlike what is normally understood ${ }^{27}$;

- nothing in the scheme indicates any kind of conclusion about the regularity of cycles; duration depends largely on the intensity of innovation, so that the cyclic process is structurally irregular ${ }^{28}$.

The following is the reasoning that leads to the second approximation of the cycle. If innovations are incorporated into new plant and equipment, spending on consumer goods will increase at least as fast as spending on capital goods. Both will expand starting from those points in the system where they exerted the first impact and will create that set of economic situations which we call prosperity. Two phenomena arise here: firstly, old businesses will react to this situation and, second, a number of them will speculate on it. Those who seek to take advantage of the situation, by speculating, act on the assumption that the rates of change they observe will continue indefinitely; such an attitude anticipates prosperity, causing a boom ${ }^{29}$. In this way, credit will not be limited to entrepreneurs and deposits will be created to finance

\footnotetext{
${ }^{26}$ Schumpeter ([1964] 2008:142).

${ }^{27}$ Schumpeter ([1964] 2008:147).

${ }^{28}$ Schumpeter ([1964] 2008:148).

${ }^{29}$ Schumpeter ([1964] 2008:150).
}

the general expansion: every loan gives rise to another one, and in the saw way a sequence of prices increases takes place. At this point, transactions join the picture that, in order to become possible, assume an expected or effective increase in prices. This is how, in the cyclic process, a secondary wave comes into play, the effects of which overlap those of the primary wave $^{30}$. The outcomes of the new wave are also more visible than the first wave, since it is easier to see an expanding fire that the torch that started it. Given this difficulty, speculation is often identified as the cause of the cycle, overlooking the innovation that began it, precisely because it is more difficult to identify ${ }^{31}$.

Even in secondary prosperity, the break is induced by a turning point in the underlying process. Any state of prosperity, however ideally limited to essential primary processes, involves a period of failures that, in addition to eliminating enterprises that are obsolete beyond any chance of re-adaptation, also gives rise to a painful readjustment process of prices, quantities and values, as the framework of a new system of equilibrium progressively emerges ${ }^{32}$. Secondary prosperity even sees risky, fraudulent or in any case unlucky initiatives take shape, that are unable to cope with the recession (entrepreneurs defined as imitators and speculators, who simply follow the situation of change). The speculative position involves many unsustainable elements, which even a minimal deterioration of the value of collateral elements will cause to fall. Inasmuch, a great deal of the day-to-day business and investments will suffer a loss as soon as prices fall, as they undoubtedly will in view of the primary process. A portion of the debt structure will also collapse. If panic and crisis prevail in this case, further adjustments become necessary: values fall and every fall brings with it yet another fall. For a certain time, the pessimistic expectation may play a decisive role, even if it subsequently does not hold up unless substantiated by objective factors ${ }^{33}$.

A cyclical pattern with four stages is consequently outlined (remember that first approximation only included prosperity and recession): prosperity, recession, depression, recovery:

Now that class of facts, whenever it is of sufficient quantitative significance, has an

\footnotetext{
${ }^{30}$ Schumpeter ([1964] 2008:151).

${ }^{31}$ Schumpeter ([1964] 2008:151).

${ }^{32}$ Schumpeter ([1964] 2008:153-154).

${ }^{33}$ Schumpeter ([1964] 2008:154).
} 
important bearing upon our schema. As long as we took no account of it [the secondary wave], we had only two phases- Prosperity and Recession-in every unit of the cyclical process, but now we shall understand that under pressure of the breakdown of the secondary wave and of the bearish anticipation which will be induced by it, our process will generally, although not necessarily, outrun (as a rule, also miss) the neighbourhood of equilibrium toward which it was heading and enter upon a new phase, absent in our first approximation which will be characterized by Abnormal Liquidation, that is to say, by a downward revision of values and a shrinkage of operations that reduce them, often quite erratically, below their equilibrium amounts. While in recession a mechanism is at work to draw the system toward equilibrium, new disequilibrium develops now: the system again draws away from a neighbourhood of equilibrium as it did during prosperity, but under the influence of a different impulse. For this phase we shall reserve the term Depression. But when depression has run its course, the system starts to feel its way back to a new neighbourhood of equilibrium. This constitutes our fourth phase. We will call it Recovery or Revival. Expansion up to equilibrium amounts then sets in and yields temporary surplus gains or eliminates the losses incident to operation at the trough amounts. (Schumpeter [1964] 2008:155).

Abandoning the hypothesis that the innovation observed is the first in history, we must conclude that each currently observable, and historically placed, cyclical phase brings with it the effects of previous waves and influences subsequent ones.

The third approximation arises from the ascertainment of the fact that since innovations are at the root of cyclic fluctuations it is impossible to think that they form a single wave movement, since the periods for gestation and absorption of effects by the economic system are not usually the same for all the innovations undertaken at any given time ${ }^{34}$.

\footnotetext{
${ }^{34}$ Schumpeter ([1964] 2008:169).
}

For our purposes, it is vital to emphasise the characteristic element of secondary prosperity: imitations and their role in further swelling the growth process. As acknowledged by Lachmann (1986:15), perhaps the most Schumpeterian of the Austrians, a «competitive process taking place within the market for a good consists typically of two phases, and in it the factors of innovation and imitation may be isolated as iterative elements» ${ }^{35}$. The expansion stage of the cycle is always characterised by the elongation of the production structure - an elongation that occurs because of investments usually associated with a specific sector of assets, i.e. the one linked with growing profit expectations, in turn stimulated by a certain kind of credit policy or change in time preferences. The success of the first investments, when the liquidation process is still not on the horizon, modifies information and the expectations of many other subjects, attracting imitators who additional investments, usually financed by credit, contribute towards intensifying the magnitude of expansion.

\section{OUR THEORY OF THE BUSINESS CYCLE (PRE- IMITATIONS)}

Let's try a synthesis. The starting point, as we have seen, is given by time preferences. At any given time, a time preference structure is matched by a production structure, i.e. a heterogeneous set of combinations of production factors, organized by human creative and entrepreneurial action in order to carry out processes that, over time, generate an output. This output should meet a demand defined by the structure of time preferences. This structure is reflected in an interest rate that, in turn, expresses the magnitude of the preference of economic agents for present goods compared to future goods.

It would therefore be wrong to start our analysis simply with monetary expansion or the lowering of the monetary interest rate. The central point, rather, is the distortion of the production structure defined by the system of preferences ${ }^{36}$, and the reasons behind such a modification.

Whatever causes set them in train, it is the intricate distortion to the structure of production that are 'the decisive factors in determining cyclical fluctuations'. These, rather than 'the superficial phenomenon of

\footnotetext{
${ }^{35}$ See also Lewin (1997:15).

${ }^{36}$ Hayek ([1929] 1966:123).
} 
changes in the value of money' - by which these distortions can be set in motion are worthy of the closer attention. (Steele 2001:146-147).

The system of time preferences is determined by the expectations of players on the market who, following their own expectations, seek to implement plans to achieve them. In a free market system, this mechanism of action takes place through the meeting of different subjects who in the process acquire new information and change their expectations. We are therefore witnessing a gradual and continuous process of re-adaptation of plans, in a natural effort to ensure that their realization 'meets' the realization of the plans of others.

In a system where there is no central bank, there is no monetary interest rate imposed by central authorities. In such a system, in which an effective free market would operate, there would simply be the natural equilibrium rate, capable of measuring the structure of time preferences. This means that price system as information transmission mechanism can actually work. What happens in the event of a unilateral modification on time preferences, such as an increase in the savings rate? This is the situation in which consumers become more future-oriented. It is thereby evident that a conflict arises between the time preferences of consumers and those of investors. Yet this also means that the equilibrium rate moves downwards, in an attempt also to orient the plans of entrepreneurs towards the future, who would therefore be encouraged to change the structure of the production process, starting with investments in more capital-intensive production plans: the new lower interest rate is 'informing' investors that new resources are available for long-term investments. These investments will be financed precisely with the new savings. The new equilibrium rate, the only signal for players on the market, allows entrepreneurs to modify their expectations and plans; it informs them that new resources are available and that investments can be implemented profitably. The entrepreneurial instinct, typically Schumpeterian and also emphasized by Spiethoff, thereby allows the re-adaptation of expectations in order to harmonize time preferences.

Consequently, without the interference of the central bank, the natural equilibrium rate (a price generated by the interaction of supply and demand and not imposed by central banks) allows the production structure to adapt to the new system of time preferences. The profit expectations of entrepreneurs, encouraged by the lower rate of interest, are not frustrated because they find a counterpart in the different attitude among consumers, who are now less oriented towards immediate consumption. In this case, the elongation of the productive structure, the expansion cycle, is sustainable because the free interaction of players does not encounter interference and plans can be adapted. This does not mean that, in the process of adaptation, errors are not encountered errors or that certain expectations will be frustrated. Preferences adaptation is a process that takes place in real time, not instantly. However, conditions exist whereby free transmission of information helps one to learn from mistakes and rearrange plans in line with the new situation. And the scenario itself will be continually changing. The re-adaptation process does not take place 'once and for all'; it is a continuous and never tamed process. Nonetheless, it can be implemented in a balanced manner only if the natural rate, generate by the demand-supply interaction, is the only signal (price) for the players, i.e. if divergent signals are not introduced from the outside which may wrongly guide decisions and make the discoordination of preferences perpetual, thereby preventing the free inter-temporal coordination mechanism of plans.

The picture is very different if a natural rate is also flanked by a monetary rate set by a central authority. In this scenario, the signal role played by the monetary rate overpowers that of the equilibrium rate, because it is immediately publicized and more visible to the players on the market: it 'anticipates' the discovery mechanism typical of the market, it creates a wall between supply a demand. The monetary rate, inasmuch, becomes one of the essential engines driving expectations and the subsequent formation of plans. A difference between the natural rate and the monetary rate, by disorienting certain agents, may therefore modify the structure of production but without this change reflecting a parallel change in time preferences. Or, another possibility is that the monetary rate may not follow a unilateral change in preferences, thereby interfering with the process of adaptation by the economic system whose own preferences have not changed.

Let us now assume starting from a situation of equilibrium, an hypothetical starting point ' 0 '. We have a natural rate that reflects the meeting of time preferences and a production structure organised accordingly. Let's also suppose that, by chance or magic, the monetary rate set by central authorities is 
the same as the equilibrium rate. In this scenario, a disequilibrium between monetary rate and equilibrium value, whereby the former is at a value lower than the second, thereby prompting entrepreneurs to lengthen the production process, may arise in two ways. The first and most immediately intuitable hypothesis is that the central authorities cut the monetary rate in the belief, typical of monetarist dogma, that lowering the interest rate sets in motion an expansion cycle without negative repercussions. In such a scenario, central bank is misleading the profit expectations of entrepreneurs, wrongly informing them that new resources are available for investments. Therefore, entrepreneurs consider it is more convenient to invest in long-term projects; however, as we shall see, their choices are wrongly guided a false signal, which, in 'hiding' the natural rate, does not allow the system to activate the necessary counter-measures to the resurgence of natural tendencies towards equilibrium typical of a regime of freedom of entrepreneurial action $^{37}$. Entrepreneurs, following interest rate manipulation, become more future-oriented, although more savings are not generated; consequently, available resources are fictitious and time preferences are changed unilaterally, leading to a disequilibrium in inter-temporal preferences; future-oriented investors and present-oriented consumers (or not as futureoriented as entrepreneurs). A change in time preferences always happens unilaterally, but when only the natural interest rate plays a role this change can be communicated to the other side of the market. The monetary interest rates does not allow the natural one to play its information transmission role.

Yet the situation whereby the monetary interest rate is below the natural rate may also occur without the intervention of central banks. In fact, the natural rate can be pushed upwards by expanding profit expectations. Entrepreneurial action, while always seeking results, may be also determined by so-called sentiment, the inkling that certain initiatives might be profitable. In this situation, entrepreneurs become future-oriented, raising the interest rate level and pushing demand for funds to begin the longer-term production processes ${ }^{38}$.

\footnotetext{
${ }^{37}$ By this we do not mean that happiness and perfect order reign in a free society. Quite the opposite. Trends towards disequilibrium are always in place. However, in a free society, the players have the opportunity to learn from their mistakes and there is the awareness that, in order to achieve their own plans, action is needed to ensure coordination with the plans of other individuals.

${ }^{38}$ It is precisely here that Hayek expresses his main criticism of his mentor Mises. For Mises, the difference between the natural rate and the monetary
}

It is an apparently unimportant difference in exposition which leads one to this view that the Monetary Theory can lay claim to an endogenous position. The situation in which the money rate of interest is below the natural rate need not, by any means, originate in a deliberate lowering of the rate of interest by the banks. The same effect can be obviously produced by an improvement in the expectations of profit or by a diminution in the rate of saving, which may drive the 'natural rate' (at which the demand for and the supply of savings are equal) above its previous level; while the banks refrain from raising their rate of interest to a proportionate extent, but continue to lend at the previous rate, and thus enable a greater demand for loans to be satisfied than would be possible by the exclusive use of the available supply of savings. (Hayek [1929] 1966:147).

In seeking the reasons for the second case introduced by Hayek, we can find one link between the Austrian economist and Schumpeter.

The reasons for this can be of very different kinds. New inventions or discoveries, the opening up of new markets, or even bad harvests, the appearance of entrepreneurs of genius who originate 'new combinations' (Schumpeter), a fall in wage rates due to heavy immigration; and the destruction of great blocks of capital by a natural catastrophe or many others. We have already seen that none of these reasons is in itself sufficient to account for an excessive increase of investing activity, which necessarily engenders a subsequent crisis; but that they can lead to this result only through the increase in the means of credit which they inaugurate. (Hayek [1929] 1966:168).

rate is always the result of monetary manipulations. Consequently, in Mises's cycle theory, monetary disorders are exogenous in nature. For Hayek, however, the central point is the distortion of the production structure that this disequilibrium brings about between the two rates; in addition, as we have seen, the difference between the two rates is not primarily due to monetary manipulations but to the structure of time preferences and the role of expectations. Therefore, the Hayekian approach can be defined as endogenous. Hayek ([1929] 1966:145-148). Hayek ([1931] 1967:35) emphasises that the primary cause of fluctuations must be sought in the changes generated in the way in which production resources are used. 
Even in this case, however, changes to preferences take place unilaterally. If, in the presence of a monetary rate, central banks do not realign the latter towards the equilibrium level in order also to encourage savers themselves to become more future-oriented by increasing saving amounts, the structure of preferences will remain disproportionate and the new inter-temporal production structure will reflect such an imbalance. In this case, therefore, expectations change before the intervention of central banks. And it is this emphasis on expectations, and their role in changing the structure of production, that allows us to explain why in 1939, ten years after his first work on business cycles, Hayek ([1939] 1975:3) argues that «a rate of profit rather than a rate of interest in the strict sense which is dominating" to explain fluctuations. In this as in the previous case, it is not monetary manipulation that plays the key role capable of altering the system of preferences by dis-coordinating plans and the structure of production. In the first situation, the crucial role is given by the manner and direction in which monetary expansion influence expectations. In the second case, on the other hand, expectations themselves divert the system away from equilibrium. The role of the central authority, in this case, would be to realign the monetary rate upwards in order to allow a rebalancing action, partly by discouraging the new demand for loanable funds and partly by increasing the monetary offer by means of additional savings.

Changing expectations, caused by (case 1) or the cause of (case 2) a monetary rate below its natural level, is - on closer inspection - a natural part of the entrepreneurial instinct emphasized by Schumpeter. The analysis of the entrepreneurial role (innovation) as a fundamental element in initiating an expansion cycle, implemented in an organic way by Schumpeter, is entirely coherent with our analysis. We are explicitly discussing the concept of expectations: entrepreneurs see opportunities for profit and take advantage of them, i.e. they have positive expectations, or, otherwise, they are future-oriented and ready to make the production process more roundabout. Some are prepared to take risks on real innovations that can create a competitive advantage for them. Others by merely imitating on the wave of enthusiasm. Still others by launching poorly grounded economic initiatives.

Let's return now to our analysis and the disequilibrium between natural and monetary rates. The situation consideration therefore encourages the onset of major investments in production assets, or capital goods, whereby the economy becomes, in general, more capital-intensive, i.e. the production period is extended ${ }^{39}$. Hayek is precisely the link $^{40}$ between the Mises's ${ }^{41}$ emphasis on the interest rate and the centrality of the disproportions created in the production structure ${ }^{42}$.

So far we have not answered, or have only hinted at an answer to the question why, under the existing organization of the economic system, we constantly find those deviations of the money rate of interest from the equilibrium rate which, as we have seen, must be regarded as the cause of the periodically recurring disproportionalities in the structure of production.

[...] It has been shown, in addition, that the primary cause of cyclical fluctuations must be sought in changes in the volume of money, which are undoubtedly always recurring and which, but their occurrence, always bring about a falsification of the pricing process, and thus a misdirection of production. (Hayek [1929] 1966:139-140).

The cardinal point of the theory is the difference created between entrepreneurial decisions and consumer choices ${ }^{43}$. In the situation in question, the funds available for investments initially do not correspond to the amount of savings. In fact, an artificially low monetary rate corresponds, on the capital market, to a higher availability of money because it translates into lower interest payable on investments.

In general it is probably true to say that most investments are made in the expectation that the supply of capital will for some time continue at the present level. Or, in other words, entrepreneurs regard the present supply of capital and the present rate of interest as a symptom that approximately the same situation will

\footnotetext{
${ }^{39}$ Hayek ([1931] 1967:35-36).

${ }^{40}$ The attempt to create a bridge between the monetary approach of WicksellMises and the analysis of Spiethoff-Cassel is explicitly mentioned in Hayek ([1929] 1966:133-134)

${ }^{41}$ Hayek ([1929] 1966:116): «The investigations of Professor Mises represent a big step forward in this direction, although he still regards the fluctuations in the value of money as the main object of his explanation, and deals with the phenomena of disproportionality only in so far as they can be regarded as consequences - in the widest sense of the term - of these fluctuations".

${ }^{42}$ Hayek ([1929] 1966:119).

${ }^{43}$ Hayek ([1933] 1975:143-148).
} 
continue to exist for some time. (Hayek [1933] 1975:142).

What Hayek says is true, and the central role of expectations is resumed. Yet, all the more, the indicator on which entrepreneurs base their choices actually does not reflect any current propensity among consumers to save ${ }^{44}$. In this way, the proportion in which producers decide to differentiate production between products for the immediate future and those for the longer term (inter-temporal production structure) does not reflect the way in which consumers intend to divide their income between savings and consumption ${ }^{45}$. It is evident that sooner or later and disequilibrium in time preferences, which is reflected in an inter-temporal production structure, will arise and the typical form will be the frustration of the expectations of one of the two groups ${ }^{46}$.

So, while entrepreneurs invest in new processes for the production of capital goods, savers are frustrated in their desire to consume, because what they want is not being produced. The forced saving ${ }^{47}$ phenomenon thereby comes about, i.e. - as a consequence of the fact that production resources were diverted from sectors close to consumers - there is a gradual reduction in the production of consumer goods and therefore an involuntary limitation of consumption ${ }^{48}$.

The entrepreneurial impetus towards new investments, on the other hand, initially involves an increase in raw material prices and consequently of the capital goods produced with them ${ }^{49}$. And the impetus must be considered as particularly violent in that the wave of the first innovative entrepreneurs is joined by the pressure of imitators described by Schumpeter, who grasp profit opportunities only in a second stage and attempt to benefit by following the 'fashion'. On a closer look, imitative speculation waves are typical of every boom stage described in history, tulip bubble in the 1600 s through to the new economy bubble in 2001 and the recent housing bubble.

At the same time, demand for labour increases, and is attracted towards the new investments, with relative wages: this leads in turn encourages demand for

\footnotetext{
${ }^{44}$ Hayek ([1933] 1975:144).

${ }^{45}$ Hayek ([1933] 1975:144-145).

${ }^{46}$ Lachmann ([1943] 1977:69) and Hayek ([1933] 1975:145).

${ }^{47}$ See Hayek (1932). See also Huerta de Soto (1998:409-413).

${ }^{48}$ Kurz (2003:191) and Hayek ([1933] 1975:145-146).

${ }^{49}$ It is evident that this upsurge, during the expansion phase of the cycle, causes the prices of raw materials and capital goods to increase more than the prices of consumer goods (Hayek [1939] 1975:29).
}

consumer goods and prices in this sector also increases. And it is therefore evident that the increase in non-monetary income will not matched an increase in real incomes, because of the inflationary effect exerted by unsatisfied demand for consumer goods.

This increased intensity of the demand for consumers' goods need have no unfavourable effect on investment activity so long as the funds available for investment purposes are sufficiently increased by further credit expansion to claim, in the face of the increasing competition from the consumers' goods industries, such increasing shares of the total available resources as are required to complete the new processes already under way. (Hayek [1933] 1975:147).

Nevertheless, in order to be sustained, this process requires credit expansion without respite - which would bring about a cumulative increase in prices that sooner or later would exceed every limit. The conflict seems to be evident when demand for consumer goods exceeds in terms of absolute value the funds available for investment. At this point, the interest rate cannot but rise, frustrating demand for capital goods precisely when their price has also risen ${ }^{50}$. A considerable part of the new plant installed, designed to produce other capital goods, remains unused since the further investments required to complete production processes cannot be made ${ }^{51}$. As a result, in an advanced stage of the boom, growth in demand for consumer goods brings down demand for capital goods ${ }^{52}$.

The entrepreneurs who have begun to increase their productive equipment in the expectation that the low rate of interest and the ample supply of money capital would enable them to continue and to utilise these investments under the same favourable conditions, find these expectations disappointed. The increase of the prices of all those factors of production that can be used also in the late stages of production will raise the costs of, and at the same time the rise in the rate of interest will decrease the

\footnotetext{
${ }^{50}$ As the rate of interest increases, the rate of profit declines (Hayek [1939] 1975:31).

${ }_{51}^{51}$ Hayek ([1933] 1975:148)

${ }^{52}$ Hayek ([1939] 1975:31).
} 
demand for, the capital goods which they produce. And a considerable part of the newly created equipment designed to produce other capital goods will stand idle because the expected further investment in these other capital goods does not materialise.

This phenomenon of a scarcity of capital making it impossible to use the existing capital equipment appears to me the central point of the true explanation of crises. (Hayek [1933] 1975:148-149, our italics).

In this way, Hayek - starting off from the Misesian base of credit expansion (suitably revised) - comes to the centrality of the scarcity of capital, just like

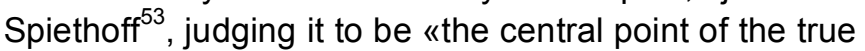
explanation of crises» (Hayek [1933] 1975:149). Hayek over the years became so convinced of the centrality of this point that he went as far as to say that «the turn of affairs will be brought about in the end by a 'scarcity of capital' independently of whether the money rate of interest rises or not» (Hayek [1939] 1975:32). As we have seen, such a situation can may actually occur even without monetary manipulation but as a result of growing profit expectations which, since the monetary rate is not allowed to rebalance itself with the natural level, cannot find counterparts in realignment with the value of the savings ${ }^{54}$.

\footnotetext{
${ }^{53}$ Hayek ([1929] 1966:41n) recognised the close relationship between his own approach and Spiethoff's. And he judged that bond to be even more significant than the one that can exist between different theories of a monetary character. In fact, as emphasised by Steele (2001:146-147), the central point of Hayekian analysis is the distortion of the production structure rather than the manipulation of the rate of interest. Monetary expansion is merely the trigger, one of the possible aspects that can set off the cyclic mechanism precisely because it is able to modify the structure of capital. Hayek writes: "Since the publication of the German edition of this book, I have become less convinced that the difference between monetary and non-monetary explanations is the most important point of disagreement between the various Trade Cycle theories. On the one hand, it seems to me that within the monetary group of explanations the difference between those theorists who regard the superficial phenomena of changes in the value of money as decisive factors in determining cyclical fluctuations, and those who lay emphasis on the real changes in the structure of production brought about by monetary causes, is much greater than the difference between the latter group and such so-called non-monetary theorists as Prof. Spiethoff and Prof. Cassel. On the other hand, it seems to me that the difference between these explanations, which seek the cause of the crisis in the scarcity of capital, and the so-called 'underconsumption' theories, is theoretically as well as practically of much more farreaching importance than the difference between monetary and non-monetary theories».

${ }^{54}$ Hayek ([1929] 1966:81-82) acknowledges Spiethoff's central role in developing a theory of fluctuations founded on disproportionalities and the scarcity of capital but he criticises his German colleague for not identifying the prime reasons for these phenomena. "Assuming that the rate of interest always determines the point to which the available volume of savings enables productive plant to be extended - and is it only by this assumption that we can explain what determines the rate of interest at all - any allegations of a
}

If the rate of interest were allowed to rise as profits rise [...], the industries that could not earn profit at this higher rate would have to curtail or stop production [...]. If $[\ldots]$ the rate of interest is kept at the initial low figure [...] and investments whose yield is not negatively affected continue in spite of the rise in final demand, the rise of profits in the late stages of production and the rise of costs will both come into play and will produce the result which the rate of interest has failed to bring about. The rise of the rate of profit on short as compared with that on long investments will induce entrepreneurs to divert whatever funds they have to invest towards less capitalistic machinery, etc.; and whatever part of the required reduction in total investment is not brought about by this diversion of investment demand towards less capitalistic type of machinery will in the end be brought about by a rise in the cost of production of investment goods in the early stages. (Hayek [1939] 1975:32-33).

Thanks to this analysis, Hayek helps us clear out every under-consumption theory.

- $\quad$ The scarcity of capital leads to partial non-use of existing capital goods.

The abundance of capital goods is the symptom of a scarcity of capital.

- This is not caused by insufficient demand for consumer goods but by excessive demand for these goods. In fact, demand for consumer goods becomes so pressing as to impede any prolonged production process, despite the fact that related means of production are available ${ }^{55}$.

Hayek explains these situations through a straightforward metaphor.

The situation would be similar to that of a people of an isolated island, if, after having partially constructed an enormous

discrepancy between saving and investments must be backed up by a demonstration why, in the given case, interest does not fulfil this function. Professor Spiethoff, like most of the theorists of this group, evades this necessary issue». See also Hayek ([1929] 1966:89-90).

${ }^{55}$ Kurz (2003:192) 
machine which was to provide them with all necessities, they found out that they had exhausted all their savings and available free capital before the new machine could turn out its product. They would then have no choice but to abandon temporarily the work on the new process and to devote all their labour to producing their daily food without any capital. Only after they had put themselves in a position in which new supplies of food were available could they proceed to attempt to get the new machinery into operation. (Hayek [1931] 1967:94) ${ }^{56}$.

Inasmuch, the economy is unable to sustain production oriented over and above its possibilities. Sooner or later, it is realised that an increase in wages is cancelled by growing inflation. In addition, demand for capital goods runs out, taking with it the overproduction in the particular sector and it is here where problems arise. Many economic initiatives set up through excessive reliance on credit cannot be completed, although the debts still have to be paid. Many companies have to be expelled from the system. Capital is scarce and banks raise interest rates. A period of adjustment and return to equilibrium begins, only it has aspects similar to a depression.

The wave dynamics typical of capitalism would be sustainable if, in typical situations of bright expectations (kaleidoscopic society), players were free to learn through interaction with each other and allow their choices to be judged on the market. Without the interference of a monetary rate, players would be forced to seek, on the market, to what extent their expectations are in line with those of other agents and therefore this would allow plans to be realised. The natural rate, although unknown as a magnitude, is dynamically given by time preferences, thereby generating a production structure in keeping with such preferences. The system would move and settle continuously. In this way, every change in the structure of production would be the adaptation to a change in time preferences, a dynamic adaptation: if profit expectations rise, pushing the natural rate upwards, the new production structure cannot begin to change until the new natural rate also convinces consumers to change their attitudes; at the same time, it is likely that not all the intense demand for new investments will be 'met' from new savings, so that the natural rate will tend to stabilise at a lower point than the initial expansionist impetus generated by entrepreneurial expectations. Demand and supply mechanism will generate, through information transmission, the new price able to link expectations of investors and consumers.

As can be seen, the situation is very different if there is a monetary rate capable of disguising the real strength of natural rate. And it is precisely the discrepancy generated between the natural and monetary value of the interest rate that tells us how long and painful cyclical dynamics will be ${ }^{57}$.

In short, a growth path is generated when time preferences change on a global scale. And this is only possible if the central element measuring time preferences - the interest rate - is left free to set itself on the market through the interaction of individuals freely exerting their entrepreneurial function in the process of meeting their needs. Typically: consumers become more future-oriented and therefore save more; the interest rate falls and this induces a change time preferences also on the part of investors who, given the lower rate, are prompted to extend the structure of the production process. The opposite but still sustainable case arises when only profit expectations increase; on a free market, where the rate is not decided arbitrarily by artificial policies of the monetary authority, the rate of interest is encouraged to rise in order to attract capital from savings and orient towards financing growth.

On the contrary, growth becomes unsustainable when a monetary interest rate, set by central monetary authorities, overcomes the information transmission mechanism otherwise played by the natural (market) rate. Even in this case, two situations may occur. On the one hand, there is the typical case of monetary expansion (inflation, lower interest rate, credit expansion). On the other hand, in the face of pressure of demand for credit by the investment sector, characterised by positive profit expectations, the monetary rate is held below the new equilibrium level.

\section{THE INTRODUCTION OF IMITATIONS IN THE MODEL. THE INEVITABILITY OF CRISIS. THE NATURAL CYCLE}

With reference to the description in paragraph $\mathrm{V}$, our vision seems simply to be a rewriting of the 
Hayekian setting, embellished by a number of aspects linked with the theory of expectations. In fact, we deliberately kept a distance from our distinctions in order to analyse them better in this section. In the previous paragraph, in fact, we limited ourselves to discussing sustainable and artificial booms, describing crisis as an inevitable consequence of growth arising from distortions in the production structure generated by imbalances in the system of preferences. Now we shall attempt to demonstrate how, on the other hand, crisis is a consequence of all stages of growth and how sustainable and artificial booms are not distinguished by the onset of depression but by its intensity and duration. Inasmuch, in our view, even in the case of 'healthy' expansion, the growth stage will be followed by a process of resettlement (crisis). This is because even for sustainable development - positive profit expectations, once the cycle has been set in motion, facilitate the appearance of speculative-imitative initiatives that, at a given point, must be liquidated in order to 'normalize' the progress of growth. What distinguishes sustainable development from an artificial boom is not the emergence of a crisis; the difference lies in the nature of the crisis and its intensity.

The crucial elements in our analysis, therefore, are expectations and the imitative process. As we have seen, Hayek ([1929] 1966:147) recognised the central role of expectations as early as 1929, when he emphasised profit expectations as the driving force behind entrepreneurial preferences, with the possibility of entrepreneurs becoming more future-oriented and thus shifting the equilibrium interest rate upwards.

Profit expectations are a key element in both the Hayekian vision of sustainable growth and in the opposite case. We will use them to describe the emergence of imitations and secondary expansion, then followed by a crisis. It is now time to see how the so-called sustainable growth in Austrian theory turned, in our view, into the natural cycle.

In the ideal situation where the monetary rate does not exist (nor the Central Bank), a lengthening of the production period, with the emergence of capitalintensive investment processes, is in fact possible when either consumers or investors become more future-oriented. If consumers are the first to change their preferences, this will take the form of growing savings followed by a decrease in the natural rate of interest, in order to attract investors to use those resources for more roundabout investments. If, on the other hand, entrepreneurs are the first to push towards lengthening of the production structure, the natural rate will rise in order to attract savers in the same direction, thereby providing necessary resources for new investments. In both cases, the natural rate is driven by a change in the structure of temporal preferences, in turn generated by different expectations. What follows is a process of sustainable development.

The role of business expectations in generating capital-intensive investments is also emphasized by Schumpeter, as is already well-known. We also saw earlier how Hayek refers explicitly to Schumpeter in highlighting the innovative and investment process that follows positive profit expectations. In this process of expansion, in accordance with the traditional version of the $A B C T$, the aspects needed to generate a crisis do not arise.

However, observation of reality leads us to emphasize that the first wave of investments it is always followed by a secondary wave of imitations and speculations. As analysed above, the pace of economic growth becomes particularly sustained when the primary wave of entrepreneurial investments is joined by a stage of secondary growth encouraged by the copy-cat instincts of imitators in search of profit and driven by 'fashion'. On a closer look, imitative speculations are typical of all the boom stages recorded in history, from the mania for tulips in the 17th century to that for new economy in 2001 and more recently for real estate. Why are imitations inevitable? This is what we have already seen as regards Lachmann's vision of capitalist development characterized by innovation and imitation. Keeping faith with subjectivism and the role of expectations, it is easy to imagine how the success of entrepreneurial initiatives is readily followed by imitators looking for success within what at first sight always seems to be a period of growth destined never to end. The primary stage of growth is characterised by investment set in motion by a limited number of entrepreneurs - those who are able to seize opportunities that go unnoticed by most people and therefore the first to change their expectations. The secondary stage is characterized by the appearance on the market of an exceptional number of imitators.

This is how we identified the first two stages in our natural cycle: primary expansion, generated by a change in the structure of time preferences and expectations (the system becomes more futureoriented), and secondary expansion characterized by imitative investments. 
If, therefore, the reality of imitative speculations cannot be eliminated, it outlines the character of the growth process by emphasizing development above the initially imagined level. As for the primary wave of investments, the second wave is also generated by profit expectations, particularly the expectation that the current situation will not change (Schumpeter [1939] 2005:145). From a quantitative point of view, moreover, imitation (secondary) investments might even be greater than the first cycle of investments since they involve a larger number of individuals, whose expectations are 'over-excited' by the boom (Schumpeter [1939] 2005:146). These secondary investments will have to be liquidated through an adjustment crisis, as we shall attempt to demonstrate.

The fact that secondary wave investments necessarily bring about their liquidation, by generating a crisis, even if for boom not induced artificially by discoordination between natural and monetary rates, apparently seems to be at odds with the traditional version of the Austrian theory, which does not admit the crisis whenever such discoordination is not at the base of the growth process. We believe, on the other hand, that - while not denying the validity of the Austrian approach - this vision should be superseded.

Let's summarise the appearance of primary expansion characterising our natural cycle. When, given positive profit expectations, entrepreneurs become more future-oriented, the natural rate of interest grows, in order to move consumer preferences in the same direction, encouraging them to save more and thereby generate resources to meet increased demand for loanable funds by investors. The mirrorimage situation arises when consumer expectations change in a more future-oriented direction; in this case, the natural rate of interest falls, informing entrepreneurs that new resources are available for investments in the longer term. Both situations, to use 'Austrian' jargon, give rise to a sustainable boom.

According to this schema, given that the lengthening of the production structure derives from a change in time preferences and market operators are not deceived by a monetary rate inconsistent with the natural rate, current investments will always find available resources to complete the business projects launched. This is precisely because, without the interference of political-monetary authorities, market operators are free to 'reveal themselves' to each other and readjust their scheme of preferences in conformity with the modified situation.
However, we have the distinct impression that this view does not take a fundamental fact into account: the rhythm of investments in real time. The Schumpeterian distinction between primary wave and secondary wave investments in this regard becomes critical. In fact, the initial increase in investments followed by a change in the structure of time preferences does not seem to generate any problem. Whether savings grow or the natural interest rate increases because of profit expectations, the timing of the onset of business ventures is necessarily dictated by the realignment of preferences. When savings increase, in fact, the problem does not arise precisely because the increased resources are the first cause of the reduction of the natural rate and the lengthening of the productive structure its consequence. All the more, if there is increased demand for loanable funds, new resources for investment will not be available until consumers decide to increase their propensity to save, that is, until the intentions of the two groups of players re-align again.

The matter changes when the second wave of investments comes into play, generated by the imitative process. It is first and foremost a natural fact, intrinsic to the boom, regardless of its type. Indeed, as Schumpeter emphasized, innovation is never generated as a mass phenomenon; on the contrary, it arises through the initiative of certain 'elect spirits' entrepreneurs - whose essence lies precisely in being able to grasp profit opportunities where others fail to see them. Subsequently, in any case, when the expansion phenomenon is already set in motion when an opportunity for profit has already been identified and grasped by some people - the prospect of grabbing a slice of the cake becomes tempting for many (the role of expectations). Not for those who have seized the opportunity and, having begun to invest, are now on the way towards reaping their reward; but for those who were bystanders and are now seeking to take part in the up stage (with a time lapse compared to the primary wave).

What form does the imitative desire take? It generates new demand for loanable funds in order to insert a more roundabout production process into the expansive cycle. This means an attempt to extend the expansion process temporarily, thereby also increasing the degree of uncertainty.

More time taken implies more things can happen - providing the possibility of greater productivity but also greater 
uncertainty. Since the value of higher order (capital) goods depends on the prospective value of the consumer goods they are expected to produce, the elapse of time, and with it the arrival of unexpected events, implies that some production plans are bound to be disappointed and thus the value of specific capital goods will be affected. (Lewin 2005:151).

And this brings us to the second stage of the natural cycle: secondary expansion. Pressure on demand for loanable funds forces the natural interest rate to rise further, in order to attract new savings to finance these investments. And this is where the role of banks joins the game to a very similar extent to that described by Schumpeter. Initially, demand for loanable funds cannot be met because preferences have not yet realigned with the new interest rate level and it is even likely that such a realignment does not actually take place.

However, the positive sentiment, the positive profit expectations, that become 'incandescent' at the end of the primary expansion stage, also plays a role as regards the action of banks. In fact, precisely because of what happens during expansion, it is highly likely that banks make 'virtual funds' available that are not backed up by real savings (as is the case during the first wave of investments), driven by expectations that the adaptation of consumer preferences (further savings) cannot but occur, precisely because of the enthusiasm generated by the boom. This returns to the Misesian phenomenon of the creation of money emphasized, with a completely different accent, by Schumpeter too.

On the other hand, it is more than likely that the long-awaited realignment does not come about. Even though the natural rate may increase, in view of the profit expectations arising from the request for second wave of investments (imitative), the likelihood that savings may increase is limited by two factors. The most obvious one is of course that consumers must also consume, hence their capacity for saving (and realignment) is objectively limited by the necessity to consume. In addition, in all likelihood, consumers will also be influenced by the general enthusiasm of the boom stage and consequently change their preferences in the opposite direction, i.e. by increasing their propensity for consumption. This is all the more true given the fact that real wages grow during the boom in order to attract workers into the new investment areas or to employ formerly unemployed workers. As in the conventional Austrian explanation, this leads to pressure in demand for consumer goods, with an initial phenomenon of forced savings and the production structure subsequent need to return to present-oriented projects (consumer goods). At this point, the growth of price and wages and the pressure on prices goods of consumer goods brings about what Hayek called the 'Ricardo effect': it helps explain why a prolonged boom stage driven by monetary expansion is likely to turn into a crisis.

[l]f the credit expansion boom does not come to an end sooner for some other reason, it must come to an end when consumer product prices advance ahead of wage and resource prices. The Ricardo effect lowers real wages and encourages a shift toward labor-intensive methods of production. A lowering of the real wage of labor makes short-term (labor-intensive) projects appear to be more profitable than long-term (capital-intensive) methods of production. The Ricardo effect may account for the sudden wave of bankruptcies among the large fixedinvestment projects that occurred toward the end of many nineteenth-century business cycles. (Moss 2005:8-9).

So, while the first wave of investments can complete its cycle because of the real existence of prior and stable funds (without which the expansion cycle would not even have started), the second wave will be frustrated by a change in consumer preferences and a banking policy influenced by expectations of profit.

The difference between sustainable growth and artificial boom, therefore, lies in the following fact: where the 'defective' cycle is triggered by a discoordination between a natural rate and a monetary rate controlled by the monetary authorities, in general many of the roundabout processes of production end up being frustrated by the onset of the Hayekian phenomenon of scarcity of capital, as described above. On the other hand, for a sustainable boom (natural cycle) generated by a change in expectations, it is only the inevitable wave of speculative-imitative investment, backed up by a banking policy influenced by a positive sentiment, which itself will later be frustrated, wherein a crisis will be the necessary action to liquidate such faulty initiatives. 
What will follow in the latter case will be a crisis (third stage of the natural cycle) but limited in terms of intensity, duration and the number of sectors involved. We could even define it as a transitory readjustment crisis, which does not cancel the beneficial effects of the previous boom but merely liquidates business ventures launched for speculative-imitative purposes. What will not follow, instead, is a fourth stage, the depression, typical of the 'defective' cycle.

We can represent the difference between the unsustainable growth and the natural cycle with the following figures.

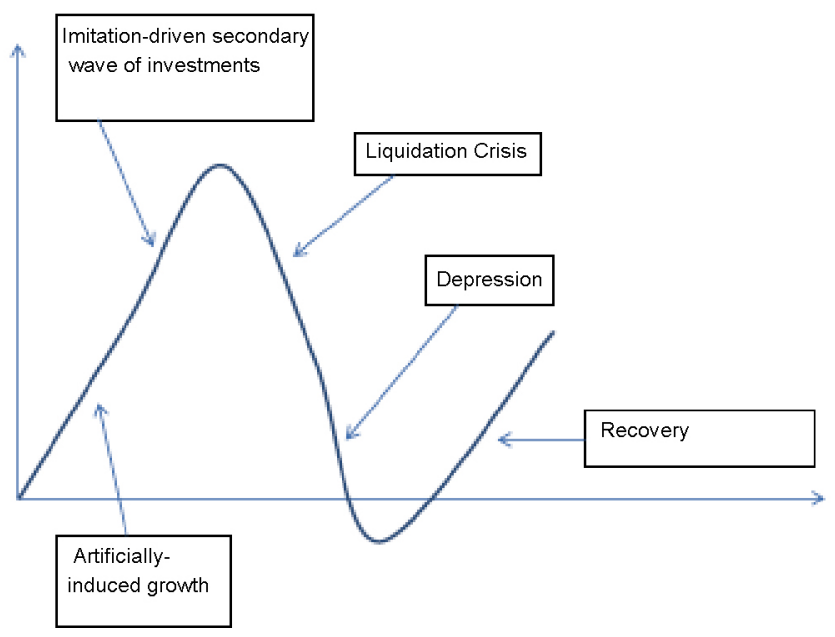

Figure 1: The Unsustainable Boom.

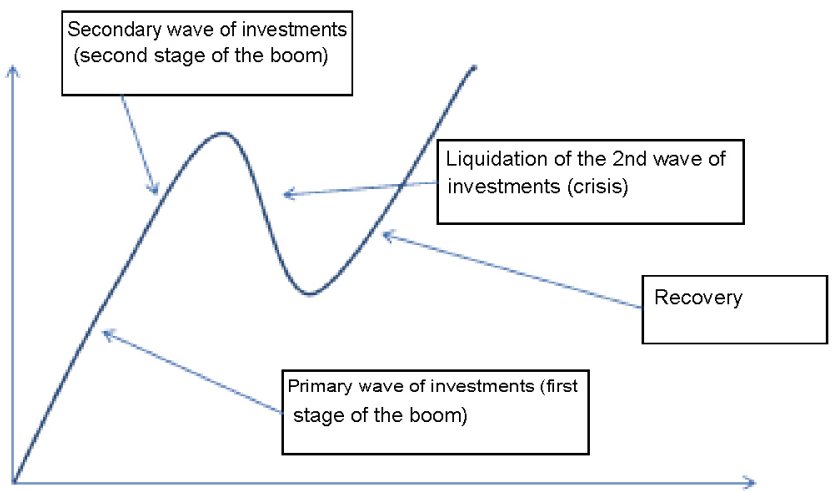

Figure 2: The Natural Cycle.

\section{CONCLUSIONS}

The analysis developed so far allows us to conclude, in a very simple way and in the wake of authoritative economists of the past, that the cyclical trend is the form that development takes in a capitalist economy.

While acknowledging the basic assumptions of the Austrian business cycle theory as valid, especially in
Hayek's version, we must also recognize that it does not suffice to eliminate the Central Bank and its 'deceptive' role exerted through the monetary interest rate in order to annihilate the cyclical dynamics of development.

The systematic introduction of 'real' expectations, acting in 'real time', in the sense advocated by Ludwig Lachmann, can only lead us towards the rediscovery of secondary investment waves (imitations and speculations) on which, in particular, Schumpeter focused. In being made possible by a banking policy sensitive to and part of the general positive sentiment of an expansion stage, they precisely match that part of the growth stage that has to be liquidated through a readjustment crisis.

We therefore believe that the Austrian distinction between sustainable and unsustainable growth is valid. What we rather seek to overcome is the belief that, in the first case, the expansion stage is not followed by a crisis. On the contrary, a liquidation crisis occurs in both cases. The difference lies in the intensity and duration of the crisis. Most of the long-term entrepreneurial projects initiated by entrepreneurs will struggle to be completed in the case of a boom generated from the outset in an 'unhealthy' manner. For growth set in motion in a 'sustainable' manner, only the imitative and speculative initiatives will not be completed. Inasmuch, the positive effects of the first part of the expansion will not be eliminated. It is merely a question of 'clearing up'. We call this instance the natural cycle. In the previous case, on the other hand, reconstruction will have to begin from a pile of rubble.

\section{REFERENCES}

Fanno, Marco. 1931. "Production Cycles, Credit Cycles and Industrial Fluctuations". Pp. 225-261 in Business Cycle Theory. Selected Texts 1860-1939. Vol. II, Structural Theories of the Business Cycle, edited by $\mathrm{H}$. Hagemann. London, UK: Pickering \& Chatto, 2002.

Ferlito, Carmelo. 2010. Dentro la Crisi. Combattere la Crisi, Difendere il Mercato. Chieti, IT: Solfanelli.

Ferlito, Carmelo. 2013. Phoenix Economics. From Crisis to Renascence. New York, NY: Nova Publishers.

Hayek, Friedrich A. von. 1929. Monetary Theory and the Trade Cycle. New York, NY: Kelley, 1966.

Hayek, Friedrich A. von. 1931. Prices and Production. New York, NY: Kelley, 1967.

Hayek, Friedrich A. von. 1932. "A Note on the Development of the Doctrine of "Forced Saving"'. Quarterly Journal of Economics XLVII: 123-133.

Hayek, Friedrich A. von. 1933. "Price Expectations, Monetary Disturbances and Malinvestments". Pp. 135-136 in Profits, Interest and Investment and Other Essays on the Theory of Industrial Fluctuations. By F.A. von Hayek. Clifton, NJ: Augustus M. Kelley, 1975. 
Hayek, Friedrich A. von. 1937. "Economics and Knowledge". Pp. 3556 in Individualism and Economic Order. By F.A. von Hayek. Chicago, IL: University of Chicago Press, 1958.

Hayek, Friedrich A. von. 1939. "Profits, interest and Investment". Pp. 3-71 in Profits, Interest and Investment and Other Essays on the Theory of Industrial Fluctuations. By F.A. von Hayek. Clifton, NJ: Augustus M. Kelley, 1975.

Hicks, John R. 1979. "Is Interest the Price of a Factor of Production". Pp. 281-295 in Modern Austrian Economics. Archaeology of a Revival. Vol. II, The Age of Dispersal, edited by P. Boettke and S. Boehm. London, UK: Pickering \& Chatto, 2002.

Huerta de Soto, Jesús. 1998. Money, Bank Credit, and Economic Cycles. Auburn, AL: Ludwig von Mises Institute.

Huerta de Soto, Jesús. 2000. The Austrian School. Market Order and Entrepreneurial Creativity. Cheltenham and Northampton, UK: Edward Elgar, 2010.

Kirzner, Israel M. 1973. Competion \& Entrepreneurship. Chicago, IL: University of Chicago Press.

Kurz, Heinz D. 2003. "Friedrich August Hayek: la teoria monetaria del sovrainvestimento". Pp. 175-207 in Friedrich A. von Hayek e la Scuola Austriaca di Economia. Edited by U. Ternowetz. Soveria Mannelli, IT: Rubbettino.

Lachmann, Ludwig M. 1940. "A Reconsideration of the Austrian Theory of Industrial Fluctuations". Pp. 267-286 in Capital, Expectations, and the Market Process. By L.M. Lachmann. Kansas City, KS: Sheed Andrews and McMeel, 1977.

Lachmann, Ludwig M. 1943. "The Role of Expectations in Economics as a Social Science". Pp. 65-80 in Capital, Expectations, and the Market Process. By L.M. Lachmann. Kansas City, KS: Sheed Andrews and McMeel, 1977.

Lachmann, Ludwig M. 1976. "From Mises to Shackle: An Essay on Austrian Economics and the Kaleidic Society". Journal of Economic Literature 14 (1): 54-62.

Lachmann, Ludwig M. 1979. "Comment: Austrian Economics Today". Pp. 64-49 in Time, Uncertainty, and Disequilibrium. Exploration of Austrian Themes. Edited by M.J. Rizzo. Lexington, D.C.: Heath and Company.

Lachmann, Ludwig M. 1982. "Why Expectations Matter". Pp. 251-269 in Modern Austrian Economics. Archaeology of a Revival. Vol. I, A Multi-Directional Revival, edited by S. GloriaPalermo. London, UK: Pickering \& Chatto, 2002.

Lachmann, Ludwig M. 1986. The Market as Economic Process. Oxford: Basil Blackwell

Lewin, Peter. 1997. "Capital in Disequilibrium: A re-examination of the capital theory of Ludwig M. Lachmann". Unpublished draft.
Lewin, Peter. 2005. "The Capital Idea and the Scope of Economics". The Review of Austrian Economics 18 (2): 145-167.

Moss, Lawrence S. 2005. "The applied economics of the modern Austrian School". Pp. 3-19 in Modern Applications of Austrian Thought. Edited by J.G. Backhaus. London, UK and New York, NY: Routledge.

Nasar, Sylvia. 2011. Grand Pursuit. The Story of Economic Genius. New York, NY: Simon \& Schuster.

O'Driscoll, Gerald and Mario J. Rizzo. 1985. The Economics of Time and Ignorance. London, UK and New York, NY: Routledge, 2002.

Rizzo, Mario J. 1979. "Disequilibrium and All That: An Introductory Essay". Pp. 1-18 in Time, Uncertainty, and Disequilibrium. Exploration of Austrian Themes. Edited by M.J. Rizzo. Lexington, D.C.: Heath and Company.

Rothbard, Murray N. 1969. Economic Depressions: Their Cause and Cure. Auburn, AL: Ludwig von Mises Institute, 2009.

Schumpeter, Joseph A. 1911. The Theory of Economic Development. New Brunswick, NJ, and London, UK: Transaction Publishers, 1983.

Schumpeter, Joseph A. 1939. Business Cycles: A Theoretical, Historical and Statistical Analysis of the Capitalist Process. Chevy Chase, MD and Mansfield Centre, CT: Bartleby's Books and Martino Publishing, 2005.

Schumpeter, Joseph A. 1964. Business Cycles. A Theoretical, Historical and Statistical Analysis of the Capitalist Process. Abridged Edition. With an introduction, by Rendigs Fels, digital edition, un document produit en version numérique par Didier Lagrange, 2008.

Spiethoff, Arthur. 1925. "Business Cycles". Pp. 109-205 in Business Cycle Theory. Selected Texts 1860-1939. Vol. II, Structural Theories of the Business Cycle, edited by $\mathrm{H}$. Hagemann. London, UK: Pickering \& Chatto, 2002.

Steele, G. R. 2001. Keynes and Hayek. The money economy. London, UK and New York, NY: Routledge.

Sylos Labini, Paolo. 1954. "Il problema dello sviluppo economico in Marx e Schumpeter". Pp. 19-73 in Problemi dello sviluppo economico. By P. Sylos Labini. Bari, IT: Laterza, 1977.

Vitello, Vincenzo. 1965. "Teoria dello sviluppo capitalistico. L'analisi di J. Schumpeter: analogie e differenze rilevanti con quella di K. Marx". Pp. 38-54 in /l pensiero economico moderno. Rome, Italy: Editori Riuniti.

\section{DOI: http://dx.doi.org/10.6000/1929-7092.2014.03.16}

(C) 2014 Carmelo Ferlito; Licensee Lifescience Global.

This is an open access article licensed under the terms of the Creative Commons Attribution Non-Commercial License (http://creativecommons.org/licenses/by-nc/3.0/) which permits unrestricted, non-commercial use, distribution and reproduction in any medium, provided the work is properly cited. 